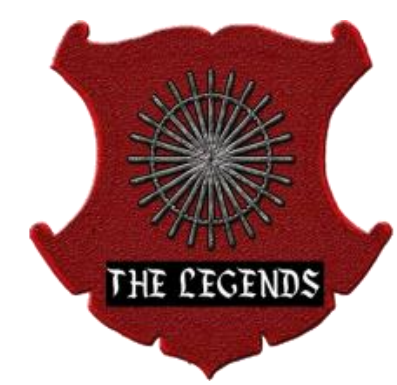

Submitted / Geliş Tarihi: 07/07/2021

\section{THE LEGENDS JOURNAL OF EUROPEAN HISTORY STUDIES( LJEHS)}

Issue / Sayı: 2 Year / Yıl: 2021

Article Type / Makale Türü: Araştırma Makalesi / Research Article Doi: http://dx.doi.org/10.29228/legends.52023

Reference / Atıf Bilgisi: Karakoç , Eren; “Antik Romalıların Gözünden İlk Avrupalı Germen Halkları”, The Legends Journal of European History Studies, S. 2, 2021, ss.41-48.

\title{
ANTİK ROMALILARIN GÖZÜNDEN İLK AVRUPALI GERMEN HALKLARI
}

\author{
Eren KARAKOÇ ${ }^{*}$
}

\section{$\ddot{O} \mathbf{z}$}

Antik Dünyanın en güçlüsü olan Roma İmparatorluğu'nu bile etkileyen, kimi zaman korkutan güçlü ve savaşçı kavimler bulunmaktaydı. Bunlar, kültürlerinin her alanına işleyen savaşçıllk özellikleriyle ve üstün fiziksel yapılarıyla Roma'nın organize ve kalabalık ordularına karşı durmuş, kimi zaman da bunları dize getirmiştir. Yunan ve Romalıların önde gelen antik yazarları, bu halklar hakkında çok ayrıntılı bilgiler sunmuşlardır. Bu halkların başında Avrupalı Germen halkları gelmektedir. Germenler, hayatlarının her yönüne işlenmiş savaşçıllk özellikleri ile Romalılara karşılaştıkları ilk zamanlardan itibaren direnmiş ve savaşmışlardır. 600 senelik inişli çıkışlı ilişkilerin ardından Batı Roma'yı yıkan en büyük kuvvetlerden biri olmuşlardır.

Anahtar Kelimeler: Antik Roma, Germen, Yunan, Avrupa.

\section{The First European Germanic Peoples Through the Eyes of the Ancient Romans}

\begin{abstract}
There were powerful and warlike tribes that influenced and sometimes frightened even the Roman Empire, the most powerful of the Ancient World. They stood against the organized and crowded armies of Rome with their martial characteristics and superior physical structures that permeate every aspect of their culture, and sometimes brought them to their knees. The leading ancient writers of the Greeks and Romans gave very detailed information about these peoples. At the beginning of these peoples are the European Germanic peoples. The Germans have resisted and fought from the first time they encountered the Romans, with their martial characteristics embedded in every aspect of their lives. After 600 years of ups and downs, they became one of the biggest forces that destroyed Western Rome.
\end{abstract}

Keywords: Ancient Roman, German, Greek, Europea

\footnotetext{
* Doç. Dr., Bahçeşehir Üniversitesi, erenkarakoc88@outlook.com. ORCID: 0000-0003-2515-2679.
} 


\section{Giriş}

Avrupa'nın güçlü ve savaşçı Germen halkları hakkındaki ilk yazılı bilgiler, kendileri yazıya sahip olmadığından ötürü M.Ö. 4. yüzyılın Yunan yazarlarından gelmektedir. Yunanlı gezgin yazar Pytheas'ın önde geldiği antik yazarlara ve arkeolojik kaynaklara göre Germenler, ilk olarak Karadeniz'in kuzeybatısında ve Tuna boylarında yaşamaktaydı. ${ }^{1}$ M.Ö. 8. yüzyılda İskitler, Orta Asya'dan bu bölgelere gelince, Germen kavimleri günümüz kuzey ve kuzeydoğu Almanya bölgelerine göçmek zorunda kalmıştır. Germenler, bu dönemden itibaren bölgedeki ormanlarda kabileler halinde yaşamışlardır. Roma Devleti'nin M.Ö. 3. yüzyıl sonlarında Avrupa içlerine yayılmaya başlamasıyla, Germen halklarının güneydeki kabileleri ile ilk karşılaşmalar yaşanmıştır. M.Ö. 202-201 arasında Helenistik Makedon Krallığı ile savaşmaya başlayan Roma Devleti, bu devletin ordularındaki Germen paralı askerlerle de karşılaşmıştır. Bu tarihlerden itibaren Germenler, siyasi, askeri, ekonomik ve kültürel olarak Roma Dünyası içine dahil olmaya başlamışlardır. M.Ö. 2. yüzyılın sonlarında, Germen halklarından olan savaşçı Cimbri ve Teutonlar, güneye ve İtalya'ya doğru sefere çıkmışlar ve bir dizi savaşın ardından Roma Devleti tarafından zorlukla durdurulabilmişlerdir.

\section{Romalılar Gözünden İlk Germenler}

Bu zaman diliminden itibaren Germenler (Germani), Romalıların gözünde özel bir yere sahip olmuştur. Yunan (Grek) ve Romalı düşüncesinde, günümüz Fransa'sını kapsayan topraklarda yaşayan Keltler/Galyalılar ile Germenler arasındaki asıl ayrım, M.Ö. 70'li yıllara dayanmıştır. Bundan önceki tarihlerde Galyalılar ile Germenler sıklıkla birbirine karıştırılmıştır. İlk defa Yunan bilgin Posidonius (M.Ö. 135-51), Germen halklarını ayrıntılı bir biçimde işlemiştir. Ancak bazı Galyalı boylar ile Germen boylarını birbirine karıştırmıştır. ${ }^{2}$

Caesar'ın Galya Savaşı yorumlarındaki Germenler ile ilgili anlatıları, Roma düşünüşünde ilk defa Germenlerin birçok halktan oluşan büyük bir etnik kimlik olarak algılanması hakkındaki ilk Romalı görüşlerini ortaya koymaktadır. ${ }^{3}$ Caesar'ın, Germenler hakkındaki düşünceleri, kısmen yabancı halkları Roma hakimiyetine almak ve onları asker olarak kullanmak arzusuyla şekillenmiştir. Örneğin seferin ilk zamanları Kelt olan Helvetii kabilesine karşı sefer düzenlemiş, bu halkı hakimiyet altına aldıktan sonra erkeklerini auxiliari askeri olarak ordusuna katmıştır. ${ }^{4}$ Caesar'ın, Galya'ya müdahalesini senato gözünde haklı çıkarmadaki siyasi arzusu, ortaya koyduğu Germen tasvirlerinin asıl sebebidir. Daha önceki Roma görüşlerinden yararlanarak ortaya koyduğu Germen imgesi, Romalılar arasında önemli derecede kalıcı bir güce sahip olmuştur. Birinci kitabında Germenleri vahşi ve barbar (feri ac barbari) olarak adlandırmış, Cimbri ve diğer bir Germen halkı olan Teutonilerin daha önceki zamanlarda yaptığı gibi İtalya'yı kolayca istila edebileceklerini söylemiştir. Bu sayede Caesar, kendini, bu halkları yenerek İtalya'yı koruyan Marius'un (M.Ö. 157-86) halefi olarak göstermiş oluyordu. ${ }^{5}$ Romalılar ile ilişkide olan Galyalılar ve tüccarların yaydığı Germenlerin muazzam kalabalıklığı, yüksek cesaretleri, muhteşem askeri eğitimleri ve savaştaki vahşilikleri

1 Pohl, Walter, "The Barbarian Successor States", In Leslie Webster; Michelle Brown (eds.). The Transformation of the Roman World, AD 400-900, British Museum Press, London 1998, 49.

2 A.L.F Rivet, Gallia Narbonensis (with a chapter on Alpes Maritimae): Southern France in Roman Times, Batsford, London 1988, 21-24.

${ }^{3}$ Caesar, Caesar's Commentaries on the Gallic and Civil Wars. (Trans. H. O. Quinsell), New York: Harper\&Brothers Ltd ,1870, 1.48 .

${ }^{4}$ Catherine Gilliver, Caesar's Gallic wars, 58-50 BC, Routledge, New York 2003, 33-35.

${ }^{5}$ Caesar, a.g.e. , 1.31.5, 33.4. 
hakkındaki söylentiler, seferin ilk zamanlarında Caesar'ın askerleri arasında büyük korkuya neden olmuştur. ${ }^{6}$ Caesar, Germenlerin süvari ve piyade olarak sağlam taktiklere ve etkili askeri güce sahip olduklarını bilmesine rağmen, ürkek askerlerini başarılı komutanlığı ile sakinleştirmiştir. ${ }^{7}$

Caesar'ın kitabında, Germen Suebi halkının kralı Ariovistus'un, Germen kahramanlığı, yenilmezliği ve askeri eğitiminden övündüğünden bahsedilir. ${ }^{8}$ Ancak Caesar'a göre Ariovistus, tipik bir barbar değildi. Eserdeki bu betimlemelerin de ortaya koyduğu üzere yüksek askeri tecrübeye ve stratejik düşünüşe sahip olan Caesar, batıdaki Galya topraklarını fethetmek için Roma politikası olan halkları birbirine kırdırma politikasını iyi kullanmış ve bu kralı, kimi Galya kabilelerini bozguna uğratması için ikna etmiştir. ${ }^{9}$

Caesar'ın, M.Ö. 55 yılında Ren Nehri'ni geçen Germen Usipetes ve Tencteri kabilelerinden olan büyükelçiler ile görüşmeleri, ona Romalılarda zaten var olan Germenler hakkındaki önyargıları yayma fırsatı da vermiştir. Bu sayede, sonraki amacı olan Germen kabilelerine karşı çıkacağı sefer için senato ve kamuoyu desteğini amaçlamıştır. Caesar'a göre, Germen büyükelçileri geri çekilme veya kaçmayı kesinlikle kabul etmemekte ve cesaretlerini bir gelenek olarak ortaya koymaktaydılar. ${ }^{10}$ Büyükelçileri her ne kadar hala Caesar ile görüşmeler yapmış olsa da, Germenler, onlardan çok daha üstün sayıda olan bir Roma süvari birliğine saldırmış ve tümünü kolaylıkla bozguna uğratmıştır. ${ }^{11}$ Germenler ile müzakerelerini yazan Caesar, Germenleri "ihanet ve hilekârlık"la (et perfidia et simulatione) suçlamıştır. ${ }^{12} \mathrm{Bu}$ açıklamasıyla Germenlere saldırısının haklılığını ispatlamaya çalışan Caesar, sonrasında Germen elçilerini hapsederek kamplarına saldırmış, kadın ve çocukları köle yapmış, erkeklerin çoğunu katletmiş ve geri kalanları mahkûm ya da belki yabancı kökenli askeri birlikler (auxiliari) olarak kabul etmiştir. ${ }^{13}$ Cumhuriyetçi senatör Cato'nun, önceden Germenler ile yapılan ateşkesin bozulması sebebiyle Caesar'ın Germenlere teslim edilmesini istediği örneğinde olduğu gibi, Romalılar'ın bir kısmı da Caesar'ın yayilmacı davranışlarını onaylamamışlardır. ${ }^{14}$

Caesar, Ren Nehri ötesinde yaşayan ve başka bir Germen halk1 olan Suebilere saldırmaktan vazgeçme kararını haklı çıkarmak amacıyla, kısmen yine Germen Ubii kabilesinin elçisi üzerinden Suebiler hakkında ayrıntılı bir etnoğrafik betimleme sunmuştur. ${ }^{15}$ Dediğine göre Suebiler, "tüm Germenler arasında en güçlü savaşçı halk" idi. ${ }^{16}$ Caesar'ın açıklamalarına göre Süebilerin tüm sosyal ve ekonomik yapıları, seferlerde savaşan askerlerini desteklemek için tasarlanmıştı. Senelik temel tarımsal süreç ve askeri birliklerin devamlılığı, savaşta kesinti olmayacak şekilde ayarlanmıştı. ${ }^{17}$ Diğer kuzey barbarları gibi Suebi'nin de özel mülkiyete veya yerleşmiş ve gelişmiş tarım anlayışına sahip olmadığı, bunun yerine süt ürünleri, sığır yetiştiriciliği ve avcılıkla yaşadığ belirtilmiştir. $^{18}$ Caesar, Suebilerin yediklerinin-içtiklerinin, günlük sert vücut geliştirme egzersizlerinin, “yaşam biçimlerinin özgürlüğünün” ve erkeklerin

\footnotetext{
${ }^{6}$ Caesar, a.g.e., 1.39.1.

${ }^{7}$ Gilliver, a.g.e., 36.

${ }^{8}$ Caesar, age, 1.36.7.

${ }^{9}$ Caesar, a.g.e., 1.44 .9

${ }^{10}$ M. Grant, Julius Caesar, Weidenfeld and Nicolson, London 1974, 87.

${ }^{11}$ Caesar, a.g.e., 4.11-12.

12 Grant, a.g.e., 92.

${ }^{13}$ Caesar, a.g.e., 4.13.6-15.5.

${ }^{14}$ Plutarkhos, a.g.e., 22.4.

${ }^{15}$ Caesar, a.g.e., 4.19, 6.10.

${ }^{16}$ Caesar, 4.1.3.

${ }^{17}$ Gilliver, a.g.e., 63.

${ }^{18}$ Caesar, a.g.e., 4.1.7-8.
} 
"görev veya disiplin" ile büyümemeleri gerçeğinin, onların gücünü artırdığını ve vücutlarını muazzam kaslı bir hale getirdiğini belirtmiştir. ${ }^{19}$ Caesar'a göre bu "barbarlar", çok soğuk olan nehirlerde yıkanır, küçük giysiler giyer ve yük hayvanlarını yetiştirmek veya ithal etmek yerine küçük evcil hayvanları yetiştirirlerdi. ${ }^{20}$ Dahası Caesar, onların kültürlerinin savaş ve güç ile ilgili olan yönlerini vurgulamıştır. Ona göre Suebiler, ekonomik ürünlerin ticaretini yapmak yerine sadece savaş ganimeti satmak için ticaret yapmışlardır. ${ }^{21}$ Süvari savaşlarında, sık sık atlarından aşağı atlamış ve yaya olarak savaşmış; eyer kullananlardan ise nefret etmişlerdir. ${ }^{22}$ Batı Avrupa'da yaşayan Galyalıların aksine, şarap ithal etmemişlerdir. İnançlarına göre şarap, erkekleri "büyük zorluklara karşı yumuşak, zayıf ve kadın gibi yapardı". ${ }^{23}$ Sınırlarını çevreleyen boş arazilerin boyutunun ise güçlerini gösterdiğine inanmışlardır.

Caesar'ın kitabında bahsettiği Germenlerin, Galyalılarla tam zıt bir biçimde gösterilişi, Germenler hakkındaki en iyi etnik Romalı görüşünü ortaya koymaktadır. Hiziplere ve sınıflara ayrılmış olan Galyalıların aksine, Germenlerin savaş için ulusal düzeyde birleştikleri görülmekteydi. Galyalılarda görüldüğü gibi ne druidler, ne kurbanlar, ne de ateş, Güneş, Ay ve ötesindekilerle ilgili tanrılarla işi olmayan Germenler, hayatlarını ağır işlere, avlanmaya ve savaş aktivitelerine adamışlardı. ${ }^{24}$ Sınırlarının dışına baskına gitmek, iyi bir egzersiz şekli ve tembellikten kaçınmanın bir yolu olarak görülmekteydi. Cinsel gelenekleri bile, savaşta en iyi olma isteği ile şekillenmiştir; iffetin boy uzunluğunu, gücü ve kasları arttırdığına inanılmaktayd $1 .^{25}$ Caesar, bu açıklamalardan sonra tekrar onların yaşam tarzlarını vurgulamıştır. Germenler kıyafetleri için hayvan derileri hazırlamış, nehirlerde banyo yapmış, yerleşik tarım yapmamış, süt, peynir ve et yemiş, özel mülke inanmamış ve yerleşim yerlerini sıklıkla değiştirerek birlik, servet eşitliği ve askeri cesareti korumayı amaçlayan tutarlı bir savaşçı kültürünü sürdürmüşlerdir. ${ }^{26}$ Germenlerde eve alınan konuklar kutsal sayılmış, onlara barınak ve yemek sağlanmıştır. Bölgeleri çevresindeki ıssız alanlar, güçlerinin göstergesi sayılırken, aynı zamanda toplum için bir güvenlik hissi yaratmıştır. ${ }^{27}$

Tüm bu anlatımlarına rağmen Caesar, genel olarak Romalılar ile komşu olan tüm halkların tek bir memleket içinde kalmayacağını düşünmekteydi. Kültürel değişimleri anlayarak, bir noktada Galyalıların, cesarette Germenleri geçeceğini ve Ren Nehri'nin ötesindeki bölgeleri de istila edeceğini ve sonrasında Roma sınırlarına saldıracaklarını iddia ederek, Galya Seferi'ni haklı göstermeyi amaçlamıştır.

M.Ö. 1. yüzyılın sonlarına doğru Roma'da başlayan iç savaşlar nedeniyle, Romalıların Germenlerle olan etkileşimleri bir süre azalmıştır. Ancak öldürülen Caesar'ın yeğeni Octavianus'un, rakiplerini egale edip Augustus olarak imparator olmasının ardından Germenler, Roma siyasi, askeri ve edebi dünyasında yeniden yerlerini alarak, sonraki klişeleri ve önyargıları şekillendirmeye başlamışlardır. ${ }^{28}$ Caesar'ın Galya Seferi'nden sonra Germenler, Roma ordularında yardımcı askerler olarak görev yapmaya başlamışlardır. Ticari ve siyasi ilişkiler de özellikle Augustus Dönemi'nin sonlarına doğru artmıştır. Hatta Augusutus'un yakın süvari korumaları, Germen kökenli olmuştur. Roma'nın ilk imparatoru olan Augustus (M.Ö.

${ }^{19}$ Caesar, a.g.e., 4.1.9.

${ }^{20}$ Caesar, a.g.e., 4.1.10, 2.2.

${ }^{21}$ Caesar, a.g.e, 4.2.1.

${ }^{22}$ Gilliver, a.g.e., 11-13.

${ }^{23}$ Caesar, a.g.e., 4.2.5.

${ }^{24}$ A. Goldsworthy, Caesar, Life of a Colossus, Orion Books, London 2007, 281-284.

${ }^{25}$ Caesar, a.g.e., 6.23.6.

${ }^{26}$ Caesar, a.g.e., 6.21.4.

${ }^{27}$ Goldsworthy, a.g.e., 285-287.

${ }^{28}$ M. P. Speidel, Riding for Caesar: The Roman Emperors' Horse Guards, (First Edition), Harvard University Press, Cambridge 1994, 15-18. 
63-M.S. 14) döneminden itibaren Roma yazarları, devlet politikası gereği Germen halklarını yanlı bir biçimde yazmaya başlamışlardır. Bu dönemde en çok değindikleri Germen halkı, sıklıkla savaştıkları Cimbriler olmuştur. ${ }^{29}$ Büyük Roma komutanı Caesar (M.Ö. 100-44), ünlü Galya Seferi (M.Ö. 58-50) hakkında yazdığı kitabında da Cimbrilerden gayet savaşçı ve güçlü bir halk olarak bahsetmiştir. ${ }^{30}$ Germen halklarından ayrıntılı olarak bahseden ilk yazarlardan olan Antik Yunan yazarı Plutarkhos (M.S. 46-120) ise Cimbriler başta olmak üzere Germenlerin savaşçılığı hakkında şunları söylemiştir:

“...Dahası, cesaretleri ve hiddetleri onları daha da karşı konulamaz hale getirdi ve savaşa ateşli bir sürat ve kudretle girdiler. Böylece onların saldırısı karşısında kimse ayakta kalamadı. Öte yandan yollarına çıkabilen herkes, onların avı ve ganimeti oldu ve Alp Ötesindeki Galya'yı korumak için var olan güçlü komutanlarıyla birlikte çok sayıda büyük Roma ordusu, şereften yoksun bir şekilde yok edildi..."31

Germenlerin cesareti ve askeri başarısı üzerine yapılan bu vurgu, Romalı yazarların yaptıkları sonraki Germen betimlemelerini de büyük oranda şekillendirmiştir.

Roma Tarihi'ni yazan ünlü Titus Livius, Caesar'ın Galya savaşlarının anlatıldığı (ele geçmeyen) anlatımını, Germenlerin yaşadığı coğrafya ve geleneklerinin betimlemesiyle başlatmıştır. Roma'nın bir diğer önde gelen tarih yazarı Tacitus'un M.S. 98'de Germenleri etnoğrafik olarak incelemesinden önce diğer yazarlar, çoğu günümüze bütün olarak gelemeyen ve Germenlerle alakalı büyük eserler yazmışlardır.. ${ }^{32}$

Roma askeri yazarı Velleius Paterculus'un (M.Ö. 19- M.S. 39) kitabındaki, ikinci Roma imparatoru olacak olan Tiberius'un (M.Ö. 42- M.S. 37), M.S. 5'de Germen Langobardi halkına karş1 yenilgisini belirttiği kısa betimlemesinde, bu halkı "normal Germen vahşiliğinden daha da fazla vahşi bir kabile" olarak tanımlamaktadır. ${ }^{33} \mathrm{Bu}$ yazar da, barbarların kendi yaşam biçimlerini eğitim yoluyla iyileştirebileceklerini belirterek, Germen Marcomanni kabilesinin kralı Marobodus'u örnek göstermiştir: "köken olarak soylu, vücut olarak güçlü, ruhu ateşli, zihin olarak değil, sadece doğum yoluyla barbar." 34 Roma Devleti'nde yetişen ve Germen kökenli bir komutan olan Arminius'un (M.Ö. 17-M.S. 21) Cherusci kabilesinin asi lideri ve Roma ordusunda eski bir auxiliari askeri-olarak, Caesar'ın Ariovistus'una benzer şekilde, her zamanki barbarların çok ötesinde bir zekaya sahip olduğundan bahsetmiştir. Caesar'ın, Suebileri yüksek askeri yeteneğe sahip düşmanlar olarak gördüğü gibi, Velleius da Marcomanni askerlerinin sürekli eğitim yoluyla neredeyse Roma standardında bir askeri disipline ulaştıklarından bahsetmektedir. ${ }^{35}$

Velleius Paterculus, Arminius'un karşılaştığı haksızlıklardan ötürü ayaklanıp Germenleri Roma'ya karşı birleştirmesi ve M.S. 9 yılında Germenia' da yapılan savaşta Roma lejyonlarını yok etmesi ile ilgili olan betimlemesinde, Germenler hakkında yanlı ve sert açıklamalarda bulunmuştur. Ona göre Germenler, lejyonların komutanı olan Varus'un önüne sahte davalar getirmiştir. Varus ise, Germen geleneklerinde var olan kan dökme ile değil de, kanun yoluyla bu davaları çözmüştür. Buna rağmen Germenler, Velleius'a göre Varus'u kandırmışlardır. Bu sebeple Varus, tedbiri elden bırakarak, Germenlere karşı yumuşamaya

\footnotetext{
${ }^{29}$ Rivet, a. g. e., 271-273.

${ }^{30}$ Caesar, Caesar's Commentaries on the Gallic and Civil Wars, (Trans. H. O. Quinsell), Harper\&Brothers Ltd, New York 1870, 1.33.4, 40.5.

${ }^{31}$ Plutarkhos, The Parallel Lives, (Trans. J. Hotmann), Loeb Classical Library, London 1921, 11.2-7.

${ }^{32}$ Livius, T., Ab Urbe Condita Libri, (Trans. A. C. Schlesinger), William Heinemann Ltd, London 1919, 104.1.

${ }^{33}$ V. Paterculus, The Roman History, (Trans. F. W. Shipley), Loeb Classical Library, London 1924, 2.106.2.

${ }^{34}$ Paterculus, a.g.e., 2.108.2.

${ }^{35}$ Paterculus, a.g.e., 2.109.1
} 
başlamıştır. Bununla birlikte Velleius, bunu bir saçmalık olarak görmüş ve şöyle demiştir: "Aslında Germenler, onları gerçekten anlayamayan birisini kolaylık kandırabilecek, kurnaz, kesinlikle vahşi ve yalan söylemek için doğmuş bir 1rktır." 36

Velleius'un bir asker olduğu ve seferlerde fazla vakit geçirdiği göz önünde bulundurulursa, Germenler hakkındaki bu ifadelerinin abartı ve yanlı olduğu anlaşılabilmektedir. Bu dönemdeki Roma yazarları tarafından Germenlerin, Roma hukuk kurallarını açıkça benimsemelerine rağmen, onların sonuç olarak güvenilmez olduğu ve Roma yönetim uygulamalarını manipüle ettikleri düşünülmüştür. Roma Devleti'ni çok sarsan Varus'un yenilgisinden sonra yazarlar, Germenlerin hilekârlık ve vahşetini vurgulamaya başlamışlar ve birçok açıdan Caesar'ın onlar hakkındaki disiplinli, ancak basit savaşçı betimlemelerini eleştirmişlerdir. Aufidius Bassus ve Yaşlı Plinus gibi, Germenler ve Germen Savaşları üzerine kitaplar yazan yazarların kayıp tarihi eserleri, Germenlerle ilgili önyargılara ve klişelere katkı sağlamıştır. Böylelikle sonraki Roma ve Avrupa tarih yazarlarının çoğu, Germenler hakkındaki önyargılı ve yanlı bilgileri kendi kitaplarında da işlemişlerdir. Genel olarak, şairler, coğrafyacılar, filozoflar ve Erken İmparatorluk Dönemi tarihçileri, Germenleri sert, vahşi, iri yarı ve savaşçı barbarlar olarak tanımlamıştır. ${ }^{37}$

Genelde etnografik bir monografi sayılan ve Germen halkları hakkında önemli bilgiler içeren Germania'nın (M.S. 98) yazarı Tacitus (M.S. 56-120), eserinde başlangıç olarak Caesar'ın Germen betimlemerinin benzerini kullanmıştır. Ancak Caesar, Germenlerin savaşçı, akıllı ve disiplinli yanlarını vurgularken, Tacitus, onların dürtüsel, duygusal davranışlarını vurgulamıştır. Birçok bakımdan Tacitus'un bahsettiği Germenler, dönem Romalıları için idealize edilen geçmişteki Romalı ataların ilkel bir versiyonu gibiydi. Ona göre Germenlerin olumsuz, dürtüsel davranışları da vardı. Tacitus, "Germani” yi cesur, savaşçı ve özgürlüğe bağlı olarak betimlerken; aynı zamanda vahşi olduklarını, disiplin ve akıl yerine, dürtüsel güçlü duygularla hareket ettiklerini belirtmiştir. ${ }^{38}$ Örneğin, Caesar'ın, Germenlerin zor işleri değerli gören tasvirinin aksine Tacitus, Germenlerin "büyük vücutlarının sadece saldırı için güçlü” olduğunu iddia etmiştir. Zor işler ve zahmetler için aynı dayanıklılığa sahip olmadıklarını, susuzluğa ve sıcağa dayanamadıklarını, sadece fakir toprak ve iklimin onları açlığa ve soğuğa karşı dayanıklı kıldığını belirtmektedir. ${ }^{39}$ Ayrıca, Germenlerin savaşla uğraşmadıkları vakitlerde avcılık ile zaman geçirdiklerini söyleyen Caesar'ın tersine Tacitus, onların savaş yapmadıkları vakit bir anda büyük değişime uğrayarak tembel, hiçbir iş yapmayan insanlara dönüştüklerini belirtir:

“...Savaşa girmedikleri zaman, avlanmak için sadece biraz zaman harcıyorlar. Ancak çok daha fazla zamanı rahatlayarak geçiriyorlar. Kendilerini uyku ve yemek yemeye adamışlar. Ocaklar, evler ve tarlaların bakımı kadınlara, ihtiyar erkeklere ve ailenin en zayıf üyelerine bırakıldığından, en cesur ve savaşçı olan erkekler hiçbir şey yapmazlar. Bu adamlar, barıștan nefret eder, ancak tembelliğe bayılırlarken, kendi doğalarında olan tutarsızlı̆̆ı da ortaya koyarlar..." 40

${ }^{36}$ Paterculus, 2.181.1

${ }^{37}$ Rivet, a.g.e., 27-38, Vergilius, Georgics, (Trans. J. Lembke), Yale University Press, London 2009, 1.474, 509; Horace, Epodes (Trans. P. Bather), Oxford University Press, Oxford 2016, 16.7; Ovidius, Tristia (Trans. A. D. Melville), Oxford University Press, Oxford 1992, 4.2.1. P. Mela, De chorographia libri tres (Trans. G. Parthey), $1867,2.26-28$.

${ }^{38}$ Tacitus, The Annals of Tacitus: Book 1-4, (Trans. A. J. Woodman and R. H. Martin), Cambridge University Press, Cambridge 2004, 29.1-5.

39 Tacitus, a.g.e., 29.3.5.

40 Tacitus, a.g.e., 29.3.6. 
Tacitus, büyük ihtimalle kasıtlı olarak, savaşçı Germen davranışındaki hızlı değişimi "hebeo" (körelmiş veya miskin-tembel) terimi ile göstererek, Romalıların ordularında auxiliari (yabancı kökenli yardımcı birlikler) olarak kullandığı savaşçı bir halk olan Batavialılar ve diğer Germenler için belirtilen "savaş için kenarda tutulan halklar" imgesine örtülü bir gönderme yapmıştır. Ona göre, savaşa girmediklerinde Germenler, kör silahlarmış gibi davranmışlar, herhangi bir işe yaramamışlardır. Romalılar, lejyoner birlikleri gibi yabancı kökenli askerlerin de ağır işlerde çalışmaya dayanması ve disiplin içinde görev yapması gerektiğine inanmaktaydı. Tacitus, anlatımında bu görüşü ortaya koymuştur.

Yukarıda değinildiği gibi Germen halkları hakkında yazan ilk Yunan ve Romalı yazarlar, bizzat bu halklar ile iletişimde olarak görüşlerini eserlerinde nakletmişlerdir. Ancak sonraki yüzyıllarda ve özellikle M.S. 4. yüzyıldan itibaren yazan Avrupalı tarihçiler hala beşyüz yıl önce oluşturulan ilk etnik portreleri sunmuşlardır. Daha sonraki yazarlar, bu başlangıç hikayelerine karşı değişik fikirler öne sürmek için geniş çaplı kültürlerarası ilişkilere sahip olamamışlardır. Yapabildikleri tek şey, eski yazarların eserlerini ve resmi devlet dökümanlarını analiz edip, konuya küçük eklemeler sağlamaları olmuştur.

\section{Sonuç}

Yukarıdaki görüşlerden anlaşıldığı üzere başta Germenler olmak üzere Roma'nın iletişime geçtiği tüm halklar, Roma düşünüş dünyasında genellikle farklı, yabancı, otantik ve "barbar" olarak algılanmıştır. Buna karşın Roma Uygarlığı, bu halklarla sosyal, siyasal, askeri ve ekonomik alanda zamanla iç içe geçmiş bir kültür yaratmıştır. Özellikle Roma ordusunda görev yapan yabancı kökenli auxiliari askerleri bu bağlamda çok önemli bir konumda bulunmuştur. Auxiliariler çoğunlukla yeni fethedilen halklar idi. Özellikle Germenler ise Romalılar için auxiliarilerin en iyileri idi. Bu askerler, Romalılar tarafından hem Roma askerleri olarak, hem de vatandaş olmayan "barbarlar" olarak görülmüştür. Ayn1 şekilde Roma tarafindan fethedilen Germen halkları da aynı düşünce kalıpları altında yaşamak zorunda bırakılmıştır. Çoğu Avrupalı tarihçi, hakimiyet altına alınan Germen halkların zaman içinde Romalılaştıklarını söylemektedir. Fethedilen halkların, yüzyıllar süren Roma hakimiyetinde bir şekilde Romalılaştıkları doğrudur. Ancak onların belirttiği şekliyle, Latinleşme anlamına gelen Romalılaşma doğru değildir. Antik yazarların belirttiği şekliyle Germenlerin hep "barbar" kalarak Romalılardan her yönden farklı oldukları da tam olarak doğru değildir. Yapılan son arkeolojik çalışmalarla, Romalı ve Germenlerin bir arada ve bir ahenk içinde yaşadığı İntercisa gibi askeri yerleşimlerin ortaya koyduğu üzere, aslında Roma İmparatorluğu içinde yaşayan ve başta Romalı ve Latinlerin de içinde olduğu tüm halklar, çok çeşitli kültürlerin genellikle özgürce bir arada yaşandığı bir dünyada yaşamışlardır. Günlük yaşantı içerisinde tüm bu halklar, mutlaka kültür alışverişinde bulunmuşlardır. Ayrıca, özellikle kültür taşıyıcısı özelliklerinden dolayı auxiliariler, her biri farklı kültürlerden gelmelerine karşın, Roma İmparatorluğu'nun bir çalışanı olarak mutlaka Roma kültürünün oluşumunu da şekillendirmişlerdir. Avrupalı tarihçilerin görüşleri olan Latin olan Roma İmparatorluğu'yla bütünleşmelerinin aksine, başta auxiliari askerleri olmak üzere tüm fethedilmiş halklar, Roma İmparatorluğu'nun günlük yaşamında derin etkiler bırakmış ve uzun bir süreç içerisinde, İmparatorlukta yaşayan tüm halklar ile birlikte Roma Uygarlı̆̆ı'nı değiştirmişlerdir. Ancak fethedilemeyen ve özellikle Ren Nehri ötesinde yaşayan Germen kavimleri Roma için süregelen tehdit unsuru olmuşlardır. İmparatorluğun ilk ve ikinci yüzyılında Germen kabileleri bir şekilde Ren Nehri'nin doğusunda tutulmuşsa da, özellikle M.S. 4. Yüzyıldan itibaren daha doğudan gelen Germen kavimleri olan Gotlar, Franklar ve Vandallar, Roma'nın daha önceden tanıdığı Germen kabilelerini hakimiyet altına alarak, Roma'ya büyük akınlara başlamışlardır. Bilindiği üzere M.S. 5. yüzyıl ise, Batı Roma'nın bu halklar tarafından parçalandığı ve yıkıldığ yüzyıl olmuştur. 


\section{Kaynakça}

Caesar, Caesar's Commentaries on the Gallic and Civil Wars. (Trans. H. O. Quinsell), Harper\&Brothers Ltd, New York 1870.

Gilliver, Catherine, Caesar's Gallic wars, 58-50 BC, Routledge, New York 2003.

Goldsworthy, A., Caesar, Life of a Colossus, Orion Books, London 2007.

Grant, M., Julius Caesar, Weidenfeld and Nicolson, London 1974.

Horace, Epodes, (Trans. P. Bather), Oxford University Press, Oxford 2016.

Livius, T., Ab Urbe Condita Libri, (Trans. A. C. Schlesinger), William Heinemann Ltd, London 1919.

M. P. Speidel, Riding for Caesar: The Roman Emperors' Horse Guards, (First Edition), Harvard University Press, Cambridge 1994.

Mela, P., De chorographia libri tres, (Trans. G. Parthey), 1867.

Ovidius, Tristia, (Trans. A. D. Melville), Oxford University Press, Oxford 1992.

Paterculus, V., The Roman History, (Trans. F. W. Shipley), Loeb Classical Library, London 1924.

Plutarkhos, The Parallel Lives, (Trans. J. Hotmann), Loeb Classical Library, London 1921.

Pohl, Walter, "The Barbarian Successor States", In Leslie Webster; Michelle Brown (eds.), The Transformation of the Roman World, AD 400-900, British Museum Press, London 1998, 49.

Rivet, A.L.F., Gallia Narbonensis (with a chapter on Alpes Maritimae): Southern France in Roman Times, Batsford, London 1988.

Tacitus, The Annals of Tacitus: Book 1-4, (Trans. A. J. Woodman and R. H. Martin), Cambridge University Press, Cambridge 2004.

Vergilius, Georgics, (Trans. J. Lembke), Yale University Press, London 2009. 